\title{
Case Files of the University of Cincinnati Fellowship in Medical Toxicology: Two Patients with Acute Lethal Occupational Exposure to Hydrogen Sulfide
}

\author{
Michael A. Policastro, MDa, Edward J. Otten, $M D^{b}$
}

aFellow, Medical Toxicology. Assistant Professor, University of Cincinnati, Division of Toxicology, Department of Emergency Medicine.

bProfessor, Emergency Medicine and Pediatric Emergency Medicine, University of Cincinnati. Director, Division of Medical Toxicology. Department of Emergency Medicine.

\section{CASE SERIES}

We are presenting cases of 2 employees of a chemical plastics manufacturing plant who experienced acute, brief, inhalational exposure to lethal concentrations of hydrogen sulfide in a confined space. Eight other coworkers not present in the immediate exposure area also presented to local health care facilities with mild complaints of headache, nausea, and dizziness, but they suffered no significant sequelae.

Patient \#1 was a 55-year-old man who, while working in a confined space, uncoupled a nozzle from a steam pipe, collapsed within one minute, and suffered cardiopulmonary arrest. He had a prior history of asthma, hyperlipidemia, coronary artery disease, and was taking lisinopril, aspirin, and lipitor. Following chest compressions and rescue breathing, both by on-scene responders and EMS, the patient's blood pressure was $210 / 110 \mathrm{mmHg}$, the pulse was $100 \mathrm{bpm}$, and ventilation was assisted at $14 /$ minute. On examination, the patient was minimally combative, with a Glasgow coma score of 6 (E1, V1, M4), with pupils $3 \mathrm{~mm}$ bilaterally and reactive to light. The patient had a small partial-thickness burn to the right chest, presumed to be a thermal burn from steam or the hot pipe. No cyanosis or pulmonary crackles were noted. Because of respiratory distress, the patient was intubated on-scene using fentanyl, diazepam, and vecuronium by the combined nurse-physician
Air EMS flight team. Post-intubation vital signs were as follows: blood pressure 130/69 $\mathrm{mmHg}$, pulse $95 \mathrm{bpm}$, respirations 14/min (assisted), and oxygen saturation $98 \%$ on $100 \% \mathrm{FiO}_{2}$. The patient's temperature on arrival to the Emergency Department (ED) was $98.2^{\circ} \mathrm{F}\left(36.8^{\circ} \mathrm{C}\right)$, where his examination remained unchanged.

Diagnostic studies were obtained in the ED. Arterial blood gas analysis on $100 \% \mathrm{O}_{2}$ showed: $\mathrm{pH} 7.24, \mathrm{pCO}_{2} 58 \mathrm{mmHg}, \mathrm{pO}_{2}$ $284 \mathrm{mmHg}$, oxyhemoglobin 97.2\%, deoxyhemoglobin $2.0 \%$, methemoglobin $0.3 \%$, and carboxyhemoglobin $0.0 \%$. The blood appeared red. An electrocardiogram revealed a narrow complex tachycardia, without Q waves, ST-segment abnormalities, or interval changes. Serum chemistries were as follows: a sodium of $139 \mathrm{mEq} / \mathrm{L}$, potassium of $4.2 \mathrm{mEq} / \mathrm{L}$, chloride of $105 \mathrm{mEq} / \mathrm{L}$, bicarbonate of $25 \mathrm{mEq} / \mathrm{L}, \mathrm{BUN}$ of $15 \mathrm{mg} / \mathrm{dL}$, creatinine of $0.9 \mathrm{mg} / \mathrm{dL}$, and glucose of $156 \mathrm{mg} / \mathrm{dL}$. Creatinine kinase (CK) was $299 \mathrm{IU} / \mathrm{L}$, CK-MB 2.2 IU/L, and troponin-I was $0.05 \mathrm{IU} / \mathrm{L}$. A complete blood count showed: white blood cells at $9.0 \mathrm{k} / \mathrm{mm}^{3}$, hemoglobin at $13.0 \mathrm{~g} / \mathrm{dL}$, hematocrit at $38.2 \%$, and platelets at $130 / \mathrm{mm}^{3}$. Coagulation studies were normal, and a chest radiograph showed adequate endotracheal tube placement, absence of pulmonary edema, and a widened mediastinal silhouette, likely due to projection artifact on an antero-posterior film.

Patient \#2 was a 53-year-old male co-worker, with a history of hypertension, but he was not receiving medical therapy. He was

Keywords: hydrogen sulfide, inhalational poisoning, sulfhemoglobin, therapeutic red blood cell exchange, hyperbaric oxygen therapy

Notes: There was no outside funding of any kind used in this study.

Acknowledgements: We would like to acknowledge Drs. Baxter, Pina, Stettler, and Yassin in their clinical care of the patients. Additionally, we would like to acknowledge Drs. Boron, Hall, and Sztankryzer for correspondence in the preparation of this manuscript. Corresponding Author: Michael A. Policastro, MD, University of Cincinnati, Division of Toxicology, Department of Emergency Medicine, 231 Albert Sabin Way, Room 1551, Cincinnati, OH 45267-0769. Email: Michael.Policastro@uc.edu 
initially working outside of the confined space and witnessed the collapse of patient \#1. He called the on-site emergency response team and, in an attempt to extract the first victim, entered the confined space without rescue respiratory equipment. While this rescue attempt was in progress, patient \#2 also collapsed, and a hydrogen sulfide detector alarm detected the presence of $\mathrm{H}_{2} \mathrm{~S}$ in the area in concentrations exceeding its upper detection limit of 100 ppm. Patient \#2 was found by emergency responders in cardiopulmonary arrest approximately 3 minutes post collapse.

On arrival to the ED, vital signs were as follows: blood pressure $170 / 100 \mathrm{mmHg}$, pulse $89 \mathrm{bpm}$, assisted ventilation at $14-16 /$ minute, temperature $99.1^{\circ} \mathrm{F}\left(37.3^{\circ} \mathrm{C}\right)$, and oxygen saturation $100 \%$ on $100 \% \mathrm{FiO}_{2}$. The patient had a Glasgow coma score of 3 , pupils were dilated $3 \mathrm{~mm}$ and minimally reactive to light, bilateral rhonchorous breath sounds were without crackles, and there were unremarkable cardiac and skin examinations.

Diagnostic studies were obtained in the ED. Arterial blood gas analysis on $100 \% \mathrm{O}_{2}$ showed: $\mathrm{pH} 7.29, \mathrm{pCO}_{2} 42 \mathrm{mmHg}, \mathrm{pO}_{2}$ $231 \mathrm{mmHg}$, oxyhemoglobin $95.7 \%$, deoxyhemoglobin $3.2 \%$, and methemoglobin $0.4 \%$. The blood appeared red. An electrocardiogram was unremarkable. Serum chemistries were as follows: a sodium of $136 \mathrm{mEq} / \mathrm{L}$, potassium of $4.0 \mathrm{mEq} / \mathrm{L}$, chloride of $105 \mathrm{mEq} / \mathrm{L}$, bicarbonate of $18 \mathrm{mEq} / \mathrm{L}, \mathrm{BUN}$ of $12 \mathrm{mg} / \mathrm{dL}$, creatinine of $1.1 \mathrm{mg} / \mathrm{dL}$, glucose of $240 \mathrm{mg} / \mathrm{dL}$, and serum lactate of $0.4 \mathrm{mEq} / \mathrm{L}$. A complete blood count showed: white blood cells at $10.9 \mathrm{k} / \mathrm{mm}^{3}$, hemoglobin at $15.0 \mathrm{~g} / \mathrm{dL}$, hematocrit at $43.5 \%$, and platelets at $108 / \mathrm{mm}^{3}$. A chest radiograph showed a partial collapse of the right upper lung lobe, absence of pulmonary edema, and proper endotracheal tube placement.

A toxicology consultation was requested and performed.

\section{What is the historical and current epidemiology of $\mathrm{H}_{2} \mathrm{~S}$ poisoning?}

The toxicity of hydrogen sulfide $\left(\mathrm{H}_{2} \mathrm{~S}\right)$ has been known for several hundred years. The occupational effects of hydrogen sulfide poisoning among cesspit and privy cleaners were first discussed by the Italian physician Bernardo Ramazzini in his treatise De morbis artificum diatribe in 1700, translated into English in 1705 [1]. Hydrogen sulfide toxicity became a public health concern in 1777 after several deaths were attributed to the Parisian sewer system. Through animal studies in the first decade of the 19th century, Dupuytren identified hydrogen sulfide as the substance of the Paris sewer deaths. Despite two separate commissions appointed to investigate the conditions of the Paris sewer systems in 1785 and 1829, deplorable conditions existed with continued off-gassing resulting in reported deaths in 1836 [1,2]. Victor Hugo described these toxic conditions in Les Miserables in 1862: "Slow asphyxia by uncleanliness, a sarcophagus where asphyxia opens its claws in the filth and clutches you by the throat; fetidness mingled with the death-rattle, mud instead of the sand, sulphuretted hydrogen in lieu of the hurricane, ordure instead of the ocean" [3].

In the United States, descriptions of hydrogen sulfide poisoning began in ways similar to the French sewer epidemics. The first American published case reports of hydrogen sulfide poisoning occurred in Kentucky in 1851; it was due to outhouse waste gas accumulation [2]. Occupational hydrogen sulfide exposures were reported by the US Department of the Interior of Mines. Reports described 58 cases of asphyxia and 99 cases of irritation in 1925 that were sustained during the refining of high-sulfur crude oil [1]. In 1929, Aves observed the effects of hydrogen sulfide poisoning in Texas oil fields and estimated there were 15-30 deaths over a 2 year period [1].

Studies of occupational $\mathrm{H}_{2} \mathrm{~S}$ exposures have continued in more recent decades. A retrospective review from Alberta, Canada's oil and gas industry revealed 221 cases of $\mathrm{H}_{2} \mathrm{~S}$ exposure from 1969 to 1973 [4]. One hundred seventy three people were transported to the hospital, and 14 victims (6\%) were dead on arrival [4]. Fuller et al. reviewed fatality reports from the U.S. Occupational Safety and Health Administration (OSHA) Integrated Management Information Systems (IMIS) from 1984 to 1994 [5]. Fifty-seven incidents were recorded with 80 fatalities; $86 \%$ occurred in confined spaces, and $23 \%$ of the deaths were due to co-worker rescue attempts [5]. A retrospective analysis revealed that 77 of the 80 deaths might have been prevented by an $\mathrm{H}_{2} \mathrm{~S}$ alarm or portable meters [5]. From 1992 to 1998, 523 U.S. civilian workers died from inhalation injury [6]. In the petrochemical and coal production industry, $66.7 \%$ of fatalities were due to sulfur and sulfur compounds, while in the mining industry, sulfur compounds accounted for $29.4 \%$ of fatalities [6]. Sulfur compounds accounted for $10.5 \%$ of fatalities in the chemical manufacturing industry [6]. Sulfur and sulfur compounds were the second most common source of mortality of fatal occupational inhalations in the U.S. [6]. Job duty analysis showed that $25 \%$ of victims were doing repair or maintenance at the time of death [6]. In an additional study of occupational hydrogen sulfide deaths, Hendrickson et al. retrospectively reviewed the United States Bureau of Labor Statistics (USBLS) database: the Census of Fatal Occupational Injuries (CFOI) [7]. In this 7 year study from 1993 to 1999, 42 hydrogen sulfide events were recorded, and they resulted in 52 deaths. There were 9 multiple victim events and $21 \%$ of all fatalities involved co-workers of an index case [7]. Forty-five of these deaths $(87 \%)$ occurred at the scene [7]. Most workers killed were white (85\%), male (98\%), and middle-aged (between 31-50 years). Additionally, duration of occupational experience appears to be a factor in mortality; death is more common in workers with less than 1 year of employment in their current duties [7]. In 2005, according to the American Association of Poison Control Centers, 1396 cases of $\mathrm{H}_{2} \mathrm{~S}$ exposure were reported. Only 1 case was an intentional exposure. 397 people were evaluated at health-care facilities, and 6 deaths were reported [8].

Occupational and community $\mathrm{H}_{2} \mathrm{~S}$ disasters have been well documented. On November 24, 1950, an oil producing plant in Poza Rica, Mexico, released large quantities of hydrogen sulfide into the air. The release resulted in the hospitalization of 320 people and the deaths of 22 people [1,9]. In 1964, 41 health related complaints (including nausea, insomnia, headache, and dyspnea) due to an increased atmospheric hydrogen sulfide air concentration of $0.4 \mathrm{mcg} / \mathrm{L}(0.3 \mathrm{ppm})$ were recorded in Terre Haute, Indiana at an industrial waste biodegradation plant $[1,9]$. 
Hydrogen sulfide liberated from an acid tank in a tannery resulted in 7 deaths and multiple injuries in Chicago, Illinois, in 1978 [10]. On March 18, 1990, in Daesan, Republic of Korea, 10,000 injuries occurred after emission of hydrogen sulfide from a chemical manufacture process; there were 100 deaths [11]. In Shanghai, China, 60,000 people were evacuated from a 3 square mile area secondary to the release of hydrogen sulfide in a gas drilling accident on December 23, 2003 [12]. Nine thousand people were injured and 243 people died. The state oil company awarded \$3.6 million dollars to the victims [12].

\section{What is hydrogen sulfide and why is it important?}

Hydrogen sulfide is a colorless gas with a characteristic odor of rotten eggs. Table 1 lists the biophysical properties of hydrogen sulfide. Hydrogen sulfide is produced by anaerobic bacteria, and it is omnipresent in our environment. A number of industries (from petroleum production to viscous rayon production) utilize hydrogen sulfide. Table 2 lists potential sources of hydrogen sulfide exposure. Additionally, hydrogen sulfide has recently been identified as a signal modulator in the endothelium of human blood vessels and for adaptation of memory in the central nervous system.

\begin{tabular}{lc}
\hline Table 1: Biophysical Properties of Hydrogen Sulfide \\
\hline Odor: & rotten eggs \\
\hline Taste: & sweetish \\
\hline Boiling point: & $-60^{\circ} \mathrm{C}$ \\
\hline Melting point: & $-85^{\circ} \mathrm{C}$ \\
\hline Relative vapor density to air: & 1.19 \\
\hline Vapor pressure at $25^{\circ} \mathrm{C}:$ & $19.6 \mathrm{~atm}$ \\
\hline Auto-ignition temperature*: & $250^{\circ} \mathrm{C}$ \\
\hline Conversion factor for hydrogen sulfide in air: & $1 \mathrm{mg} / \mathrm{m}^{3}=0.717 \mathrm{ppm}$, \\
& or $1 \mathrm{ppm}=1.4 \mathrm{mg} / \mathrm{m}^{3}$ \\
\hline
\end{tabular}

*Auto-Ignition: Lowest temperature at which a chemical will ignite. Adapted from references [9,13-18]

Table 2: Sources of Hydrogen Sulfide

\begin{tabular}{ll}
\hline natural gas & petrochemical factories \\
\hline crude petroleum & oil and gas wells \\
\hline coke over plants & manure pits \\
\hline waste management & sewers \\
\hline paper manufacturing & volcanic gases \\
\hline hot springs & tanneries \\
\hline stagnant water & food processing \\
\hline viscous rayon factories & iron smelters \\
\hline
\end{tabular}

Adapted from references $[1,4,7,9,13,14,16,17,21,71,72]$

\section{How does hydrogen sulfide exert its toxic effects?}

Hydrogen sulfide is a primary cellular toxin. Hydrogen sulfide interacts with cytochrome c oxidase, disrupting mitochondrial metabolism and ultimately leading to central neurological and respiratory dysfunction.

Three pathways exist for the metabolism of hydrogen sulfide. The primary pathway is oxidation of hydrogen sulfide to sulfite, followed by renal excretion. The second, and likely cytotoxic, pathway involves hydrogen sulfide interacting with various metalloproteins and reducing disulfide bridges of proteins, likely through reactive oxygen and sulfur species. Finally, a methylation pathway is involved in the production as well as the metabolism of hydrogen sulfide. Depending on the clinical scenario, a cycle of endogenous production as well as exogenous hydrogen sulfide detoxification aligns in a delicate balance to produce physiologic or pathologic symptoms [1,13-16].

\section{What are the clinical signs and symptoms of $\mathrm{H}_{2} \mathrm{~S}$ poisoning?}

The clinical picture of hydrogen sulfide poisoning is determined by the route, duration, and concentration of exposure. The primary route of toxicity is through inhalation [1,3-16]. Gastrointestinal and dermal absorption is negligible [14,16,17]. The 1979 Sub Committee on Hydrogen Sulfide sought to clarify the temporal definitions of clinical exposure for hydrogen sulfide [1]. "Acute" refers to a single massive exposure, usually at $>1000$ ppm. "Subacute" exposures are caused by moderate continuous $\mathrm{H}_{2} \mathrm{~S}$ levels of 100-1000 ppm. "Chronic" refers to intermittent to low-to-moderate dose exposures of 50-100 ppm [1].

Hydrogen sulfide primarily affects the nervous and respiratory system. In acute poisoning, several case reports examine the clinical syndrome of immediate "knockdown," sometimes also termed the "slaughterhouse sledgehammer" $[1,14,18,19]$. Loss of consciousness occurs with inhalational exposures to 500-1000 ppm $\mathrm{H}_{2} \mathrm{~S}[1,14-16,18]$. Death occurs primarily as a result of central respiratory arrest $[1,13-16]$. Mortality rates of $6-8 \%$ in acute hydrogen sulfide poisoning have been reported from a series of 152 patients in China $[15,20]$. Table 3 describes various physiologic parameters with corresponding hydrogen sulfide concentrations.

Hydrogen sulfide is a significant mucous membrane irritant. A mild irritant keratoconjuctivitis, termed "sour gas eye," occurs with a subacute $\mathrm{H}_{2} \mathrm{~S}$ exposures of $25 \mathrm{ppm}[1,16,17,22]$. Prolonged or intermittent exposures up to $100 \mathrm{ppm}$ may result in a more severe keratoconjuctivitis with long-term disability $[14,16,22]$. Permanent blindness may result from chronic exposures, but it is unlikely $[14,16,22]$. The characteristic warning, "rotten egg" odor, abates with persistent exposure to levels above $100 \mathrm{ppm}$ due to olfactory fatigue $[1,9,13,14,16,17,21]$.

The initial pulmonary response to a subacute hydrogen sulfur exposure is carotid body-mediated hyperpnea $[1,13]$. Continued exposure may result in non-cardiogenic pulmonary edema and central respiratory arrest $[1,13,14,16]$. With acute, severe hydrogen sulfide exposure, pulmonary edema may not develop because of the rapidity of respiratory arrest $[1,13,14,16]$. 


\section{Table 3: Clinical Effects of Hydrogen Sulfide Exposure}

\begin{tabular}{ll}
\hline Concentration (ppm) & Clinical Effects \\
\hline 0.025 & Detectable odor \\
\hline 0.15 & Offensive odor \\
\hline 10 & Sore eyes \\
\hline $20-30$ & Strong intense odor \\
\hline 50 & Conjunctival irritation \\
\hline 100 & Olfactory fatigue \\
\hline 250 & Prolonged exposure may cause death \\
\hline $300-500$ & Pulmonary edema, immediate threat to life \\
\hline 500 & Dizziness, respiratory arrest imminent \\
\hline 1000 & Unconscious immediately, imminent death \\
\hline
\end{tabular}

Adapted from $[14,15,18]$

With subacute or chronic exposures, no evidence exists for the development of reactive airway disease or exacerbation of underlying obstructive pulmonary disease; however, interstitial fibrosis following subacute $\mathrm{H}_{2} \mathrm{~S}$ exposure has been reported.

Considerable evidence exists of acute and long-term neurological defects related to varying hydrogen sulfide exposures. Effects include dizziness, coma, seizures, headaches, mood dysfunction, and memory loss [1,4,14-17,19,23-27]. Interestingly, basal endogenous hydrogen sulfide production via cystathionine $B$-synthase (CBS) appears to function as a neuromodulator of long-term potentiation of the hippocampus via increased NMDAmediated excitatory responses [28-30]. $\mathrm{H}_{2} \mathrm{~S}$ does not seem to function as either a retrograde second messenger (such as nitric oxide or carbon monoxide) in the hippocampus, or act via a cGMP response [28-30]. How endogenous $\mathrm{H}_{2} \mathrm{~S}$ evokes active synaptic responses remains to be determined.

Elevated hydrogen sulfide concentrations in fibroblasts and myoblasts have been found in patients with Down syndrome (trisomy 21) [31]. This may be related to over expression of the CBS gene located on chromosome 21 [31]. It is theorized that some of the neurological dysfunction in Down syndrome patients (such as impaired color perception, muscle hypotonia, and mental retardation) is due to the chronically elevated endogenous levels of hydrogen sulfide inhibiting synaptic responses [31]. Animal studies suggest that subacute hydrogen sulfide exposure results in long-term memory dysfunction [32]. Similarly, a retrospective analysis of 19 patients with subacute and chronic hydrogen sulfide exposure without loss of consciousness revealed long-term mood and memory dysfunction [32]. While basal levels of hydrogen sulfide are required for normal neurological function, it appears that high concentrations of hydrogen sulfide exert deleterious effects on the CNS.

Endogenous hydrogen sulfide induces vasorelaxation via ATPsensitive $\mathrm{K}^{+}$channels $[30,33]$. How this system interacts with exogenous hydrogen sulfide, however, is unknown. Case reports regarding various dysrhythmias and blood pressure changes have been recorded for acute and subacute exogenous hydrogen sulfide exposures [14]. Debate continues as to whether chronic exposure results in long-term ischemic or hypertensive cardiovascular disease [14]. The dermal, hepatic, hematopoietic, renal, and reproductive organ systems have negligible toxicities with hydrogen sulfide exposure $[13,14,16-18,21]$.

\section{What is the differential diagnosis for a "knockdown" poison and why is this clinically important?}

Immediate incapacitation of a patient is an important historical fact to assist in determining the etiology of acute syncope when patients present with suspected poisoning. Additionally, rapid acute incapacitation is an important concern for the safety of rescue workers operating in confined spaces. Early warning properties, such as a bad odor, may fail to provide reliable protection from harm involving overwhelming exposures. The clinician or pre-hospital rescue worker should consider chemical asphyxiation as a primary etiology in these circumstances. These toxins often function either as simple asphyxiants, displacing oxygen from the environment, or by disrupting mitochondrial energy production [34]. One should use appropriate rescue gear with a self contained breathing apparatus when extracting victims from a closed space or with environmental concerns regarding the potential toxins listed in Table 4 [34].

Clinically, much confusion, misinformation, and panic may occur when receiving victims of a suspected gas poisoning. For instance, the "worried well" may begin to present simultaneously. The clinician, in conjunction with the on-scene commander, must coordinate care plans as well as determine scene safe zones. Variables such as vapor density, plume direction, ignition temperature, and oxygen concentration should be considered when dealing with a hazardous materials situation.

\section{Are hydrogen sulfide poisoning and sulfhemoglobin related?}

A great deal of confusion exists in the medical literature regarding hydrogen sulfide exposure and sulfhemoglobinemia.

\begin{tabular}{ll}
\hline Table 4: Immediate “Knockdown" Agents \\
\hline methane & acetylene \\
\hline propane & argon \\
\hline nitrogen & helium \\
\hline nitrous oxide & nitrogen dioxide \\
\hline carbonmonoxide & carbon dioxide \\
\hline cardon disulfide & carbonyl sulfide \\
\hline organophosphates & hydrogen cyanide \\
\hline sodium azide & hydrogen sulfide \\
\hline Adapted from references $[9,21,34,73]$ & \\
\hline
\end{tabular}


Sulfhemoglobin (SulfHB), a greenish pigment derived from native hemoglobin, was first commented upon by Hoppe-Seyler in 1863 $[1,35,36]$. Sulfhemoglobinemia has been reported in post mortem decomposing bodies after drug ingestion, in vitro studies of hydrogen sulfide, and isolated inhalational in vivo case reports of hydrogen sulfide poisoning.

In vitro studies with $\mathrm{H}_{2} \mathrm{~S}$ or aryl amines reacting with oxyhemoglobin produce sulfhemoglobin [36,37]. Sulfhemoglobin may also be produced by the action of hydrogen peroxide on methemoglobin [36,37]. Sulfhemoglobinemia produces an abnormal visible spectral peak in the region of $620 \mathrm{~nm}$ [36]. Other hemoglobinopathies producing similar patterns include hemoglobin $\mathrm{M}$ and methemoglobinemia. Laboratory differentiation among these compounds has been accomplished by the addition of either cyanide or carbon monoxide [38].

Only $0.5 \mathrm{~g} / \mathrm{dL}$ of sulfhemoglobin is required to cause central cyanosis as compared to $5 \mathrm{~g} / \mathrm{dL}$ of deoxyhemoglobin or $1.5 \mathrm{~g} / \mathrm{dL}$ of methemoglobin [43]. Thus, the clinical degree of cyanosis is greater for sulfhemoglobin than methemoglobin in equal amounts. Tissue oxygenation is facilitated by a rightward shift in the oxygen-hemoglobin dissociation curve [36,41]. But at higher levels of SulfHB, the functional anemia of reduced oxygen affinity may overwhelm any improvement in oxygen unloading at the tissue level.

Sulfhemoglobin has been reportedly induced by the ingestion of various compounds, including acetanilide, phenacetin, nitrates, trinitroluene, dapsone, sulfonamides, metoclopramide with $\mathrm{N}$ acetylcysteine, and the original formulation of Bromo-Seltzer® (potassium bromide, acetanilide, and caffeine) [41-43].

A few case reports suggest that hydrogen sulfide poisoning may cause in vivo sulfhemoglobinemia, but it should be noted that this possibility remains controversial [44,45,51]. In 1981, orthopedic casting plaster and a 90\% sulfuric acid solution, found in a hospital's plumbing system, caused a chemical reaction that resulted in a release of $\mathrm{H}_{2} \mathrm{~S}$. An exposure victim developed cyanosis and was reported to have a SulfHB level of 7.9\% [44]. Hoidal et al commented on two workers suspected of sulfhemoglobinemia after exposure to asphalt fumes [45]. No direct sulfhemoglobin level was measured, and this inference was based on a calculated oxygen saturation gap, suggesting mitochondrial cellular dysfunction and abnormal hemoglobin species. More recently, a 2004 Italian publication suggests that SulfHB levels can be used as a marker for hydrogen sulfide exposures in natural thermal baths [51]. Outside of these case reports, the collective opinion is that sulfhemoglobinemia is not produced with inhalational $\mathrm{H}_{2} \mathrm{~S}$ exposure $[1,35,46]$. At physiologic $\mathrm{pH}$, hydrogen sulfide exists as the HS- anion $[13,14]$. The sulfide anion does not exist in sufficient proportions to interact with hemoglobin to form sulfhemoglobin. Additionally, the HS- anion is a reducing agent, whereas SulfHB is formed in instances of oxidant stress.

Diagnostically, sulfhemoglobinemia may be detected by cooximetry $[36,39,40]$. The following co-oximeters can detect sulfhemoglobin (SulfHB) fractions: the AVL 912 Co-Oxylite (AVL Scientific Corp., Roswell, GA); CIBA Corning 270 (Ciba Corning
Diagnostic Corp., Medfield, MA); Radiometer OSM 3 (Radiometer, Copenhagen, Denmark); and IL-Model 682 (Instrumentation Laboratory, Lexington, MA) [36,39,40].

The medical treatment of sulfhemoglobinema is controversial. Often, patients can tolerate markedly elevated levels of sulfhemoglobin [38]. In more severe cases with signs of impaired tissue oxygenation, such as cardiac dysfunction, exchange transfusion has been advocated by some authors, while others recommend only removal of the primary offending agent [38].

Upon review of the available data, it is the opinion of the authors that acute hydrogen sulfide poisoning does not cause sulfhemoglobinemia. The pathophysiology of hydrogen sulfide poisoning exists beyond any interaction of hydrogen sulfide with hemoglobin, and treatment should focus on other mechanisms of action. In vitro or post mortem study analysis of sulfhemoglobinemia cannot be applied to the clinical entity associated with acute hydrogen sulfide gas poisoning.

\section{What diagnostic studies confirm $\mathrm{H}_{2} \mathrm{~S}$ toxicity?}

No single readily available biological diagnostic test reliably confirms exposure to $\mathrm{H}_{2} \mathrm{~S}$ in a clinically efficient manner. Indirect laboratory findings, however, may be suggestive of hydrogen sulfide toxicity. Hall and Rumack suggest that venous hyperoxemia may point to a cytochrome oxidase poison [25]. If available, environmental air sample analysis may be beneficial at the scene of exposure $[14,17,47]$. Air sample analysis methods for hydrogen sulfide include:

- gas chromatography with either electrochemical or flame ionization detection,

- ion chromatography,

- sulfide-ion selective potentiometric titration,

- iodometric methods,

- methylene blue colorimetric or spectrophotometric method,

- lead acetate or mercuric chloride spot paper or tile method $[14,14,47]$.

Measurements of thiosulfate levels in blood, tissue, and urine have been used to confirm $\mathrm{H}_{2} \mathrm{~S}$ exposures [48]. However, in a small case series of 3 patients, blood thiosulfate concentrations were not detected in victims who survived a confirmed $\mathrm{H}_{2} \mathrm{~S}$ exposure $[49,50]$. Kage et al. compared rat data to human non-fatal $\mathrm{H}_{2} \mathrm{~S}$ exposures, and they suggested that urine thiosulfate was better than blood thiosulfate as an indicator for hydrogen sulfide exposure $[49,50]$. Normal reference urinary thiosulfate levels are $\leq 8 \mu \mathrm{g} / \mathrm{ml}[15,49-51]$. Other etiologies of elevated levels include excess dietary sulfur ingestion or selenium oxidase deficiency [52]. Low concentrations of urinary thiosulfate have been seen even with confirmed acute severe exposure to hydrogen sulfide due to rapid respiratory arrest and limited sulfide absorption and metabolism $[1,49,50]$. Postmortem levels of blood sulfide detected by ion-specific electrodes in confirmed lethal $\mathrm{H}_{2} \mathrm{~S}$ exposures have ranged from $1.7-3.75 \mu \mathrm{g} / \mathrm{mL}$. Other authors suggest normal blood sulfide concentrations of $0.03 \mu \mathrm{g} / \mathrm{ml}$ and suggested lethal levels, 
determined from autopsy samples, at $0.8-5.0 \mu \mathrm{g} / \mathrm{ml}[48,53]$. Limitations of post-mortem sulfide values include age of samples, sample transport mechanism, duration of exposure, in vivo post mortem metabolism of hydrogen sulfide, and putrefaction of the deceased with microbial hydrogen sulfide production [19].

\section{Case Continuation}

Toxicology consultation was performed in the Emergency Department. The chemical plant's industrial health officer was contacted to review objective findings. No other possible chemicals (including arsenic, stibine, cyanide, or nitrates) were present by history. The ambient oxygen concentration was normal. An extensive multi-disciplinary discussion ensued regarding therapeutic options. Nitrites were not administered due to the amount of time elapsed since the event. The recommendation from toxicology was hyperbaric oxygen therapy. Additionally, it was suggested that if neurological dysfunction continued, whole blood exchange transfusion might be beneficial [21].

Patient \#1 and patient \#2 received hyperbaric oxygen therapy. The patients had 3 ATAs of $100 \%$ oxygen for a total of 50 minutes with two scheduled 15 minute air breaks. Both patients were decompressed at a rate of $1 \mathrm{psi} / \mathrm{min}$ to 2.0 ATA for a total of 40 minutes with an intervening 10 minute ambient air break. Patient \#1 had some mild neurological improvement, a response to stimulation that included localization of pain. Patient \#2 continued to remain completely unresponsive. Because of persistent neurological dysfunction, both patients underwent red blood cell exchange transfusion at the end of day \#1 post-exposure. Urinary thiosulfate and blood sulfide specimens were irretrievable from the original laboratory specimens.

\section{What therapeutic modalities exist to treat acute $\mathrm{H}_{2} \mathrm{~S}$ exposure?}

Toxicity from $\mathrm{H}_{2} \mathrm{~S}$ exposure involves reaction of the HS- anion with the mitochondrial ferric iron of heme a3 of the heme/ copper terminal cytochrome oxidase, resulting in impaired oxidative metabolism from disrupted electron chain transport $[1,9$, $13-15,18,25,26,54]$. Proposed therapeutic interventions include: administration of nitrites, oxygen, hyperbaric oxygen, persulfide reagents, and whole blood exchange transfusion $[1,9,13-15$, $18,21,25,26,38,40,45,55-59]$.

Nitrite therapy for acute hydrogen sulfide poisoning appears to have first been studied in 1956 by Gunter [1]. Pretreatment with nitrites in various animal models of hydrogen sulfide poisoning improved survival. The postulated mechanism is nitriteinduced methemoglobinemia, with resultant binding of sulfur to the ferric ion of methemoglobin to form sulfmethemoglobin. Several authors recommend nitrites as the primary treatment of choice, regardless of time from $\mathrm{H}_{2} \mathrm{~S}$ exposure $[1,5,25,26]$. The recommended dose of sodium nitrite in adults is $300 \mathrm{mg}$ IV in a 10 $\mathrm{mL}$ volume $(30 \mathrm{mg} / \mathrm{mL})$, which should be given over at least 5 minutes to avoid hypotension. Pediatric dosing is $0.2-0.33 \mathrm{~mL} / \mathrm{kg}$ $(6-10 \mathrm{mg} / \mathrm{kg})[25,60]$. Severe elevations in methemoglobin levels are unlikely at this dosage [25]. Additionally, outside of the formation of sulfmethemoglobin, other nitrite-induced mechanisms were suggested to be involved to disrupt the sulfur-iron complex of the disrupted cytochrome oxidase system, nitrite-induced vasodilation, or indirect stimulation of cytochrome oxidase $[1,3,15]$. Critics of nitrite therapy suggest that the lifetime of sulfide in the blood is brief and no benefit is seen with nitrite administration except immediately proximate to the time of injury $[4,15,58]$.

In 1969, Smith studied cobalt nitrate and other cobalt salts as antidotes for sulfide toxicity, and a survival benefit was found in mice [61]. As noted previously, the proposed mechanism of action was through the production of methemoglobin [1,61]. However, divalent cobalt, which did not produce methemoglobin, continued to provide protection against hydrogen sulfide in mice. Cobalt possibly acted in a manner similar to its mechanism in cyanide detoxification, and therefore hydroxycobalamin may be effective as an antidote in hydrogen sulfide poisoning. Future animal studies are needed to evaluate survival benefit and toxicity.

A minority of authors advocate $100 \%$ oxygen at atmospheric pressure as a primary treatment modality [58]. Smith et al. refuted this in a mouse study that demonstrated no protective or therapeutic effect against hydrogen sulfide poisoning [1]. However, no author suggests withholding oxygen as an adjuvant treatment modality.

Hyperbaric oxygen (2.5-3 ATA) in a few case reports and animal studies has been suggested as an adjuvant treatment in patients with persistent neurological injury or oxygenation defects $[23,59,62]$. Proposed mechanisms of benefit include oxidation of glutathione, competitive inhibition of sulfide-cytochrome binding, and minimization of central neurological injury due to reactive sulfur and oxygen species $[59,62]$. However, HBO therapy is not without potential risks, such as barotrauma, oxygen toxicity, seizures, and possible worsening of pulmonary edema. No specific recommendations have been made with regard to duration of acute treatment or number of treatments for hydrogen sulfide poisoning. And a collective study analysis is difficult because of the heterogeneity of protocols and patients. In the absence of a contraindication, toxicologists should not withhold hyperbaric oxygen therapy from patients with a significant hydrogen sulfide exposure. Formal neuropsychiatric testing (used with carbon monoxide-poisoned patients) may help to select patients who were exposed to subacute or chronic $\mathrm{H}_{2} \mathrm{~S}$ and who remain symptomatic at the time of presentation as potential $\mathrm{HBO}$ candidates.

Therapeutic red cell exchange (TREX) may also be used to treat $\mathrm{H}_{2} \mathrm{~S}$ toxicity. TREX has been used in toxicology for poisoning from aniline, arsine, chloramines, salicylates (infants), theophylline (neonates), sodium chlorate, carbon monoxide, cyanide and, methemoglobinemia $[57,63-70]$. TREX is performed either manually or is automated with the addition of replacement fluids that include crystalloids, albumin and/or plasma. Plasma exchange is another possibility at the time of red blood cell exchange $[65,67,70]$. The American Society for Apheresis considers exchange transfusion in poisonings as a category II intervention: generally acceptable, but best used as an adjuvant to primary therapy [65]. A search of the medical literature since 1926 yielded only a few case reports and some non-English 
language studies regarding therapeutic red cell exchange for poisoning. We did not locate any case reports or studies specific to the use of TREX for hydrogen sulfide poisoning. Perhaps some of the rationale for TREX in $\mathrm{H}_{2} \mathrm{~S}$ poisoning relates to the theoretical concern for sulfhemoglobinemia and its irreversible binding of sulfur to hemoglobin. However, this is an unlikely mechanism with inhalational $\mathrm{H}_{2} \mathrm{~S}$ poisoning. TREX may have benefits outside any replacement of SulfHB with normal hemoglobin by removing sulfides from the intravascular space. Complications from the procedure include volume shifts, hypocalcemia from excess citrate, hypothermia, dilutional coagulopathy, and transfusion reactions, including anaphylaxsis. Contraindications to TREX include severe anemia, pre-existing coagulapathy, or severe hypotension $[65,67,70]$.

Additional therapies suggested for hydrogen sulfide poisoning have included $\alpha$-keto-glutarate and dithionitrile, but minimal animal studies or outcome data have been performed [15].

\section{Case Conclusion}

Patient \#1 was extubated on day 2 post-injury with no focal neurological dysfunction. He had no cranial nerve dysfunction, sensory, or motor paralysis. The patient experienced psychiatric symptoms including acute anxiety, grief reaction, and depression. He developed transient thrombocytopenia, which was felt to be dilutional. There was some transient chest pain, but it was ruledout for acute myocardial infarction. Patient \#1 was discharged from the hospital on day 5 post-exposure, and psychiatric followup was recommended. He continues to suffer from anxiety and depression since the event.

Patient \#2 remained in a persistent vegetative state with severe cerebral edema, multiorgan system dysfunction, and coagulopathy despite aggressive resuscitative measures. Ultimately, care was withdrawn and he expired on day 4 post-exposure.

\section{What conclusions or guidelines can be suggested from the cases and literature reviewed?}

- Hydrogen sulfide poisoning is primarily a clinical diagnosis.

- Acute, subacute, and chronic hydrogen sulfide poisoning may have persistent neuropsychiatric morbidity.

- While urinary thiosulfate and blood sulfide levels provide variable results in confirmed exposures, environmental monitoring is the best likely source for real-time analytical confirmation.

- Controversy remains on the best treatment options. Due to the lack of prospective studies, adequate evidentiary suggestions are limited. However, the following suggestions are the opinions of the authors after case and literature review.

- Nitrites currently remain the drug of choice to treat acute hydrogen sulfide exposure. The duration of benefit post-exposure remains controversial. However, nitrites may have a beneficial role outside of methemoglobin formation.
- Hydroxycobalamin might be a viable antidote for acute hydrogen sulfide poisoning and warrants future study.

- Early HBO therapy may help with acute and long-term neuropsychiatric morbidity. Further studies are required to determine long-term outcome measures.

- Therapeutic red blood cell exchange (TREX) has been suggested as an alternative adjuvant treatment. Its usefulness in hydrogen sulfide is limited because of its side effects and operator availability. Additionally, the rationale of TREX in $\mathrm{H}_{2} \mathrm{~S}$ poisoning seems based on the assumption that hydrogen sulfide formed sulfhemoglobin. It is the opinion of the authors that clinically relevant sulfhemoglobinemia is not formed with inhalational hydrogen sulfide exposure. Thus, TREX therapy is unlikely to achieve a demonstrable benefit in this manner. TREX may have benefits to hydrogen sulfide poisoned patients through alternative mechanisms, but it should remain as a secondary or tertiary adjuvant therapy.

- The role of endogenous hydrogen sulfide production and metabolism deserves further investigation.

- With only two patients receiving HBO and TREX, it is not possible to determine the optimal therapeutic options or to suggest which intervention provided the most benefit, if any. Patient \#2 possibly had a more severe initial poisoning than patient \#1, and this initial poisoning may have resulted in the vastly differing clinical outcomes.

The authors have no potential financial conflicts of interest to report.

\section{REFERENCES}

1. Smith RP, et al. Hydrogen sulfide. National Research Council on Medical and Biological Effects of Environmental Pollutants. 1979;1-183.

2. Mitchell CW, Davenport SJ. Hydrogen sulfide literature. Public Health Reports. 1942;30:1-13.

3. Hugo V. Les Miserables. Boston: Little Brown and Company; 1887.

4. Burnett WW, King EG, Grace M, Hall WF. Hydrogen sulfide poisoning: Review of 5 years' experience. Can Med Assoc J. 1977;117:1277-1280.

5. Fuller DC, Suruda AJ. Occupationally related hydrogen sulfide deaths in the United States from 1984 to 1994. J Occup Environ Med. 2000;42:939-942.

6. Valent F, et al. Fatal work-related inhalation of harmful substances in the united states. Chest. 2002;121:969-975.

7. Hendrickson RG, et al. Co-worker fatalities from hydrogen sulfide. American Journal of Industrial Medicine. 2004;45:346-350.

8. Lai MW, Klein-Schwartz W, Rodgers GC, Abrams JY, Haber DA, Bronstein AC, Wruk KM. 2005 Annual Report of the American Association of Poison Control Centers' National Poisoning and Exposure Database. Clin Toxicol (Phila). 2006;44: 803-932. 
9. Deng JF. Hydrogen sulfide. In: Sullivan Jr., JB and Krieger, GR Clinical Environmental Health and Toxic Exposures. Philadelphia, Lippincott, Williams, and Wilkins, 2001;716-721.

10. Langford NJ, Ferner RE. Episodes of environmental poisoning worldwide. Occup Environ Med. 2002;59:855-860

11. UNEP Production and Consumption Branch APELL (Awareness and Preparedness for Emergencies on a Local Level) Disaster Database. [accessed 19 Jan 2007]. http://www/unep.fr/ pc/apell/disasters/database/disastersdatabase.asp.

12. Boden C. China offers $\$ 3.6$ million to gas disaster survivors. Seattle Times. 2004.

13. Beauchamp RO, Bus JS, Pop JA, Boreiko CJ, Andjelkovich DA. A critical review of the literature on hydrogen sulfide toxicity. Critical Reviews in Toxicology. 1984;13:25-97.

14. Council SR. Toxicology profile for hydrogen sulfide (update). US Department of Health and Human Services. Agency for Toxic Substance and Disease Registry. 2006;1-201, Appendices A-201.

15. Snyder JW, Safir EF, Summerville GP, Middleberg RA. Occupational fatality and persistent neurological sequelae after mass exposure to hydrogen sulfide. Am J Emerg Med. 1995;13: 199-203.

16. Svendsen K. Hydrogen sulfide. The Nordic Expert Group for Criteria Documentation of Health Risks from Chemicals and The Dutch Expert Committee On Occupational Standards. 2001; $1-31$.

17. Chou S. United Nations Environmental Programme, the International Labor Organization, and The World Health Organization. Hydrogen sulfide: Human health aspects. 2003.

18. Holstege CP, Ison GE, Kirk MA. Cyanide and hydrogen sulfide. In: Goldfrank LR, Flomenbaum NE, Lewin NA, Hoffman RS, Howland MA, Nelson LS, eds. Goldfrank's toxicologic emergencies. New York: The McGraw-Hill Companies, Inc; 2006; 1718-1721.

19. Milby TH, Baselt RC. Hydrogen sulfide poisoning: Clarification of some controversial issues. Am J Ind Med. 1999; 35:192-195.

20. Woodall GM, Smith RL, Granville GC. Proceedings of the hydrogen sulfide health research and risk assessment symposium October 31-November 2, 2000. Inhal Toxicol. 2005;17:593-639.

21. Leiken K. Hydrogen sulfide. In: Ford M, Delaney KA, Ling L, and Erickson T, Clinical Toxicology. Philadelphia, WB Saunders, 2001;712-715.

22. Lambert, Timothy W, Goodwin, Verona M, Stefani D, Strosher L. Hydrogen sulfide (h2s) and sour gas effects on the eye. A historical perspective. Science of the Total Environment. 2006;367:1-22.

23. Belley R, et al. Hyperbaric oxygen therapy in the management of two cases of hydrogen sulfide toxicity from liquid manure. CJEM. 2005; 7:257-261.

24. Dorman DC, Moulin FJ, McManus BE, Mahle KC, James RA, Struve MF. Cytochrome oxidase inhibition induced by acute hydrogen sulfide inhalation: Correlation with tissue sulfide concentrations in the rat brain, liver, lung, and nasal epithelium. Toxicol Sci. 2002;65:18-25
25. Hall AH, Rumack BH. Hydrogen sulfide poisoning: An antidotal role for sodium nitrite? Vet Hum Toxicol.

1997;39:152-154.

26. Stine RJ, Slosberg B, Beacham BE. Hydrogen sulfide intoxication. A case report and discussion of treatment. Ann Intern Med. 1976;85:756-758.

27. Tvedt B, Skyberg K, Aaserud O, Hobbesland A, Mathiesen T. Brain damage caused by hydrogen sulfide: A follow-up study of six patients. Am J Ind Med. 1991;20:91-101.

28. Abe K, Kimura H. The possible role of hydrogen sulfide as an endogenous neuromodulator. J Neurosci.

1996; $16: 1066-1071$.

29. Dello Russo C, Tringali G, Ragazzoni E, Maggiano N, Menini E, Vairano M, Preziosi P, Navarra P. Evidence that hydrogen sulphide can modulate hypothalamo-pituitary-adrenal axis function: In vitro and in vivo studies in the rat.

J Neuroendocrinol. 2000;12:225-233.

30. Leffler CW, Parfenova H, Jaggar JH, Wang R. Carbon monoxide and hydrogen sulfide: Gaseous messengers in cerebrovascular circulation. J Appl Physiol. 2006;100:1065-1076.

31. Kamoun P, Belardinelli MC, Chabli A, Lallouchi K, Chadefaux-Vekemans B. Endogenous hydrogen sulfide overproduction in down syndrome. Am J Med Genet A. 2003;116: 310-311.

32. Kilburn KH. Effects of hydrogen sulfide on neurobehavioral function. South Med J. 2003;96:639-646.

33. Tang G, Wu L, Liang W, Wang R. Direct stimulation of $\mathrm{k}(\mathrm{atp})$ channels by exogenous and endogenous hydrogen sulfide in vascular smooth muscle cells. Mol Pharmacol. 2005;68: 1757-1764.

34. Kuschner WG, Blanc PD. Gases and other inhalants. In: LaDou J, ed. Occupational and environmental medicine.

International: McGraw-Hill; 1997;572-583.

35. Curry SC, Gerkin RD. A patient with sulfhemoglobin? Ann Emerg Med. 1987; 16:828-830.

36. Park CM, Nagel RL. Sulfhemoglobinemia. Clinical and molecular aspects. N Engl J Med. 1984;310:1579-1584.

37. Park CM, Nagel RL, Blumberg WE, Peisach J, Magliozzo RS. Sulfhemoglobin. Properties of partially sulfurated tetramers. J Biol Chem. 1986;261:8805-8810.

38. Lu HC, Shih RD, Marcus S, Ruck B, Jennis T. Pseudomethemoglobinemia: A case report and review of sulfhemoglobinemia. Arch Pediatr Adolesc Med. 1998;152:803-805.

39. Wu C, Kenny MA. A case of sulfhemoglobinemia and emergency measurement of sulfhemoglobin with an osm3 co-oximeter. Clin Chem. 1997;43:162-166.

40. Zijistra WG, Buurama A, Zwart A. A performance of an automated six wavelenght photometer (radiometer osm3) for routine measurement of hemoglobin deratives. Clin Chem. 1998; $34: 149-152$.

41. Aravindhan N, Chisholm DG. Sulfhemoglobinemia presenting as pulse oximetry desaturation. Anesthesiology.

2000;93:883-884.

42. Brandenburg RO, Smith HL. Sulfhemoglobinemia; a study of 62 clinical cases. Am Heart J. 1951;42:582-588. 
43. Noor M, Beutler E. Acquired sulfhemoglobinemia. An underreported diagnosis? West J Med. 1998;169:386-389.

44. Peters JW. Hydrogen sulfide poisoning in a hospital setting. JAMA. 1981;246:1588-1589.

45. Hoidal CR, Hall AH, Robinson MD, Kulig K, Rumack BH. Hydrogen sulfide poisoning from toxic inhalations of roofing asphalt fumes. Ann Emerg Med. 1986;15:826-830.

46. Haggard, Howard W. The toxicology of hydrogen sulphide. The Journal of Industrial Hygiene and Toxicology. 1925;7: 113-121.

47. Agency UEP. Toxicology review of hydrogen sulfide. In support of summary information of the integrated risk information systems 2003.

48. Knight LD, Presnell SE. Death by sewer gas: Case report of a double fatality and review of the literature. Am J Forensic Med Pathol. 2005;26:181-185.

49. Kage S, Ikeda H, Ikeda N, Tsujita A, Kudo K. Fatal hydrogen sulfide poisoning at a dye works. Leg Med (Tokyo). 2004;6: 182-186.

50. Kage S, Takekawa K, Kurosaki K, Imamura T, Kudo K. The usefulness of thiosulfate as an indicator of hydrogen sulfide poisoning: Three cases. Int J Legal Med. 1997;110:220-222.

51. Nikkanen HE, Burns MM. Severe hydrogen sulfide exposure in a working adolescent. Pediatrics. 2004;113:927-929.

52. Tan WH, Eichler FS, Hoda S, Lee MS, Baris H, Hanley CA, Grant PE, Krishnamoorthy KS, Shih VE. Isolated sulfite oxidase deficiency: A case report with a novel mutation and review of the literature. Pediatrics. 2005;116:757-766.

53. Chaturvedi AK, Smith DR, Canfield DV. A fatality caused by accidental production of hydrogen sulfide. Forensic Sci Int.

2001;123:211-214.

54. Wallace KB, Starkov AA. Mitochondrial targets of drug toxicity. Annu Rev Pharmacol Toxicol. 2000;40:353-388.

55. Belley R, Bernard N, Cote M, Pacquet F, Poitras J. Hyperbaric oxygen therapy in the management of two cases of hydrogen sulfide toxicity from liquid manure. Can J Emer Med. 2005; $7: 257-261$.

56. Osbern LN, Crapo RO. Dung lung: A report of toxic exposure to liquid manure. Ann Intern Med. 1981;95:312-314.

57. Osborn HH, Henry G, Wax P, Hoffman R, Howland MA. Theophylline toxicity in a premature neonate-elimination kinetics of exchange transfusion. J Toxicol Clin Toxicol.

1993;31:639-644.

58. Ravizza AG, Carugo D, Cerchiari EL, Cantadore R, Bianchi GE. The treatment of hydrogen sulfide intoxication: Oxygen versus nitrites. Vet Hum Toxicol. 1982;24:241-242.
59. Whitcraft DD, 3rd, Bailey TD, Hart GB. Hydrogen sulfide poisoning treated with hyperbaric oxygen. J Emerg Med.

1985;3:23-25.

60. Nelson K, Robinson DL. A case review: Near fatal residential hydrogen sulfide exposure. Air Med $J$.

2002; $21: 46-48$.

61. Smith RP. Cobalt salts: Effects in cyanide and sulfide poisoning and on methemoglobinemia. Toxicol Appl Pharmacol.

1969; $15: 505-516$.

62. Smilkstein MJ, Bronstein AC, Pickett HM, Rumack BH. Hyperbaric oxygen therapy for severe hydrogen sulfide poisoning. J Emerg Med. 1985;3:27-30.

63. Danielson C, Houseworth J, Skipworth E, Smith D, McCarthy L, Nanagas K. Arsine toxicity treated with red blood cell and plasma exchanges. Transfusion. 2006;46:1576-1579.

64. Golden PJ, Weinstein R. Treatment of high-risk, refractory acquired methemoglobinemia with automated red blood cell exchange. J Clin Apher. 1998;13:28-31.

65. Gorlin JB. Therapeutic plasma exchange and cytapheresis in pediatric patients. Transfus Sci. 1999;21:21-39.

66. Manikian A, Stone S, Hamilton R, Foltin G, Howland MA, Hoffman RS. Exchange transfusion in severe infant salicylism. Vet Hum Toxicol. 2002;44:224-227.

67. McLeod BC. The technique of therapeutic apheresis. Removal of abnormal blood elements may succeed when all else fails. J Crit Illn. 1991;6:487-495.

68. Perrin C, Debruyne D, Lacotte J, Laloum D, Bonte JB, Moulin M. Treatment of caffeine intoxication by exchange transfusion in a newborn. ACTA Paediatr Scand.

1987;76:769-781.

69. Tauberger G, Karzel K, Roezel V. [the efficacy of blood exchange transfusions in the treatment of acute cyanide poisoning (author's transl)]. Arch Toxicol. 1974;32:189-197.

70. Valbonesi M, Bruni R. Clinical application of therapeutic erythrocytapheresis (tea). Transfus Sci. 2000;22:183-194.

71. Reiffenstein RJ, Hulbert WC, Roth SH. Toxicology of hydrogen sulfide. Annual Review of Pharmacolgy and Toxicology. 1992;109-134.

72. Yant WP. Sulphide in industry occurrence, effects, and treatment. Am J Public Health Nations Health. 2000;20: 598-608.

73. Done AK. The toxic emergency: Calling for help. Emerg Med. 1979; 11:127-129, 134-128, 142-125 passim.

74. Duong TX, Suruda AJ, Maier LA. Interstitial fibrosis following hydrogen sulfide exposure. Am J Ind Med. 2001;40:221-224. 